Article

\title{
Silver Nanoparticles Biosynthesized with Spruce Bark Extract-A Molecular Aggregate with Antifungal Activity against Candida Species
}

\author{
Anca Delia Mare ${ }^{1,+}{ }^{+}$Adrian Man ${ }^{1,+}\left(\mathbb{D}\right.$, Cristina Nicoleta Ciurea ${ }^{1,2, *} \mathbb{C}$, Felicia Toma ${ }^{1, *}$, Anca Cighir ${ }^{1,2}$, \\ Mihai Mareș ${ }^{3}{ }^{\circ}$, Lavinia Berța ${ }^{4}\left(\mathbb{C}\right.$ and Corneliu Tanase ${ }^{5}(0)$
}

1 Department of Microbiology, "George Emil Palade" University of Medicine, Pharmacy, Sciences and Technology of Târgu Mureș, 38 Gheorghe Marinescu Street, Mureș, 540139 Târgu Mureș, Romania; anca.mare@umfst.ro (A.D.M.); adrian.man@umfst.ro (A.M.); anca.cighir@umfst.ro (A.C.)

2 Doctoral School, George Emil Palade University of Medicine, Pharmacy, Science and Technology of Târgu Mureș, 38 Gheorghe Marinescu Street, 540139 Târgu Mureș, Romania

3 Laboratory of Antimicrobial Chemotherapy, Ion Ionescu de la Brad University of Life Science, 8 Aleea Mihail Sadoveanu, 700489 Iași, Romania; mihaimares@fungi.ro

4 Department of General and Inorganic Chemistry, "George Emil Palade" University of Medicine, Pharmacy, Sciences and Technology of Târgu Mureș, 38 Gheorghe Marinescu Street, Mureș, 540139 Târgu Mureș, Romania; lavinia.berta@umfst.ro

5 Department of Pharmaceutical Botany, “George Emil Palade” University of Medicine, Pharmacy, Sciences and Technology of Târgu Mureș, 38 Gheorghe Marinescu Street, Mureș, 540139 Târgu Mureș, Romania; corneliu.tanase@umfst.ro

check for
updates

Citation: Mare, A.D.; Man, A.; Ciurea, C.N.; Toma, F.; Cighir, A.; Mareș, M.; Berța, L.; Tanase, C. Silver Nanoparticles Biosynthesized with Spruce Bark Extract-A Molecular Aggregate with Antifungal Activity against Candida Species. Antibiotics 2021, 10, 1261. https://doi.org/ 10.3390/antibiotics10101261

Academic Editors: Marcello Iriti, Elena Maria Varoni and Sara Vitalini

Received: 2 October 2021

Accepted: 15 October 2021

Published: 17 October 2021

Publisher's Note: MDPI stays neutral with regard to jurisdictional claims in published maps and institutional affiliations.

Copyright: (c) 2021 by the authors. Licensee MDPI, Basel, Switzerland. This article is an open access article distributed under the terms and conditions of the Creative Commons Attribution (CC BY) license (https:/ / creativecommons.org/licenses/by/ $4.0 /)$.
* Correspondence: cristina.ciurea@umfst.ro (C.N.C.); felicia.toma@umfst.ro (F.T.)

+ These authors share the first authorship.

\begin{abstract}
Due to their high content of biomolecules, combined with silver's well known antimicrobial potential, silver nanoparticles biosynthesized using spruce bark (AgNP SBEs) demonstrate antibacterial and antioxidant activity, making them a versatile option for developing new antimicrobial agents that might be used for medical treatment or as adjuvants for the classical agents. This study aims to analyze if silver nanoparticles (AgNPs) mediated by spruce bark extract (SBE) and silver salts (AgNP SBE Acetate, AgNP SBE Nitrate) presents antifungal activity against five different Candida spp., synergistic activity with fluconazole, and if they interact with some virulence factors of $C$. albicans. AgNP SBEs presented MICs (minimum inhibitory concentrations) for all the five tested Candida spp. AgNP SBEs inhibited the growth of C. parapsilosis, C. krusei, and C. guilliermondii, exerted synergistic activity with fluconazole for C. parapsilosis and C. guilliermondii, and inhibited biofilm production for C. albicans, C. auris, and C. guilliermondii. MICs of AgNP SBE Acetate significantly inhibited the production of germ tubes of $C$. albicans. The expression of $C$. albicans SAP2 gene was down-regulated by the short-time treatment with MICs of AgNP SBE Acetate, while ALS3 and HSP70 genes were up-regulated by the AgNPs MICs. These results emphasize the potential of using the AgNP SBEs as treatments/adjuvants options, not only against the redundant $C$. albicans but also for the non-albicans Candida species (which are not as frequently involved in human pathologies, but, sometimes, can be more aggressive).
\end{abstract}

Keywords: biosynthesis; biofilm; silver nanoparticles; spruce bark; synergism; SAP2; ALS3; HSP70

\section{Introduction}

According to the World Health Organization, infections caused by drug-resistant microorganisms are responsible for at least 700,000 deaths every year, and, if no action will be taken until 2050, this number might increase to 10 million deaths every year [1]. Millions of fungal infections are diagnosed annually, leading to approximately 1,350,000 deaths each year [2]. Since the therapeutic options for these multidrug-resistant microorganisms 
are very limited, there is an urgent necessity for developing new antimicrobial agents that might be used for treatment or, as adjuvants for the classical agents.

The noble metals such as silver, gold, and platinum, despite the fact that they are considered as non-essential elements for the human organism, are often taken into consideration for several chemical, biological, and medical applications (drug delivery agents, imaging agents, cosmetic applications, antimicrobial medical devices, etc.) due to their antimicrobial, antioxidant, and anti-inflammatory activity [3-7]. In the last few decades, there has been a growing interest in the medical community for different applications of metal-based nanoparticles. Due to their small size, controlled forms, and the possibility of functionalizing their surfaces with other different molecules, the nanoparticles can provide new solutions for solving persistent medical problems, such as the increasing antimicrobial resistance $[5,8,9]$. Silver nanoparticles appear to be one of the most promising options due to silver's antimicrobial potential and since the development of bacterial resistance against silver is a very rare phenomenon. It is understood that a bacterial generation needs to undergo three different mutations in three different bacterial systems at the same time to develop resistance against silver, which is unlikely to appear $[10,11]$.

The chemical and physical synthesis of metal-based nanoparticles are considered laborious, expensive, and require toxic reductants (e.g., hydrazine, sodium borohydride) $[9,12]$. Nanoparticle biosynthesis, especially using different plant extracts, is an interesting option as it is an easy, low-cost method with minimum environmental impact. The plant extracts provide different active agents (such as phenolic, alcoholic compounds, flavones, enzymes, proteins, alkaloids, terpenoids) that facilitate the silver ions reductions [9]. Some of the plant's biomolecules (flavonoids, phenols) can coat the nanoparticles very effectively, preventing their agglomeration, and by this, the small-sized nanoparticles maintain their ability to penetrate through the bacterial or fungal cell wall [13]. This antimicrobial mechanism, along with the production of reactive oxygen species, membrane alterations, and DNA damages, is already described as antimicrobial mechanism of silver nanoparticles. More detailed studies, with similar methodologies, are necessary to fully understand the antifungal mechanisms of the bio-nanoparticles [11,14-16].

Candida spp. are considered as the major human fungal pathogens, causing a large variety of infections, from superficial to systemic ones, with the potential of becoming lifethreatening infections especially in immunocompromised patients $[17,18]$. The plasticity and the multiple virulence factors of Candida spp. allows them to transform, quickly and easily, from harmless commensals to pathogens. Candida albicans adhesion on the host cells and their invasion into the cells is associated with ALS (agglutinin-like sequence) genes [19]. Als3 is a protein localized on the surface of the hyphae produced by C. albicans, that helps it to adhere not only to the host cells but also to the extracellular protein matrix. C. parapsilosis presents five ALS genes that are involved in the adhesion to the host cells, while C. glabrata presents a different epithelial adhesin (Epa) that promotes this attachment [19-21]. C. albicans secretes hydrolytic enzymes such as proteinases (Saps), lipases (Lip), phospholipases (PL), which are also involved in the adhesion and the penetration into the host cells. Hsps (heat shock proteins), which mediate the response to stress for C. albicans, are involved in the dispersion of these cells inside the biofilms and the susceptibility to antifungal agents [19].

Lately, there is an arising number of studies that focus on the antifungal activity of the silver nanoparticles, and some of their antifungal mechanisms are described. Even if the studies are abundant, most of them are focused especially on Candida albicans, as it is the most frequent yeast involved in human infections. However, there is a lack of information regarding the antifungal activity and their antifungal mechanisms against other Candida spp., such as the newly discovered multiresistant strain C. auris, or C. krusei, a long-known drug-resistant strain [2,22-25].

In previous studies, silver nanoparticles synthesized using spruce bark extract and silver acetate/nitrate were characterized, and their antibacterial, antioxidant activity was described. Since the AgNP SBEs proved to be a versatile antibacterial option for developing 
new agents with potential to become treatment/adjuvant agents for bacterial infections, we considered important to evaluate if this potential might be extended as an antifungal option, also. [26,27]. This study aims to analyze if these nanoparticles present antifungal activity, against five different Candida spp. (C. albicans, C. parapsilosis, C. krusei, C. auris and C. guilliermondii), if they might exert synergistic activity with different concentrations of fluconazole, and if they might interact with some virulence factors of C. albicans (biofilm production, germ tubes formation, the expression of SAP2, ALS3, and HSP70 genes).

\section{Results}

\subsection{Synthesis and Characterization of the AgNP SBEs}

Synthesis and characterization of the spruce bark extract (SBE) and AgNP SBEs (AgNP SBE Ac-silver nanoparticles synthesized using spruce bark and silver acetate, AgNP SBE Nit-silver nanoparticles synthesized using spruce bark and silver nitrate) were previously described, in studies conducted by the same collective of authors [26,27]. Briefly, the spruce bark presented a total polyphenol content of $23.67 \pm 1.45 \mathrm{mg}$ GAE/g dry weight [26], with compounds as vanillic acid and taxifolin being identified in the SBE [28]. The biosynthesis of the AgNP SBEs was confirmed by the specific color modification and by UV-Vis analysis (maximum absorbance at $411 \mathrm{~nm}$ for AgNP SBE Ac, respectively at $431 \mathrm{~nm}$ for AgNP SBE Nit). The FTIR analysis of the AgNP SBEs indicated the presence of -O-H bonds (phenolic compounds), $-\mathrm{C}-\mathrm{H}$ (aldehydes), $>\mathrm{C}=\mathrm{O},-\mathrm{OH}$ carboxylic, aromatic ethers and carboxylate ions $\left(\mathrm{COO}^{-}\right)$. The transmission electron microscopy images proved that AgNP SBEs were spherical, small size particles (44.02 nm for AgNP SBE Ac, respectively $75.91 \mathrm{~nm}$ for AgNP SBE Nit) [26]. As the antibacterial activity of the SBE [28], as well as the antibacterial and antioxidant activity of the AgNP SBEs [26] were previously demonstrated, the next step of our studies was to further investigate (from a microbiological point of view) these AgNPs, by evaluating their antifungal activity against Candida spp.

\subsection{Antifungal Activity of the AgNP Mediated by Spruce Bark Extracts (SBE)}

Both the AgNP SBEs presented 50\% MICs and 100\% MICs for all the five Candida spp. (Table 1). Overall, AgNP SBE Nit presented lower MIC values than the AgNP SBE Ac, for both $50 \%$ and $100 \%$ inhibition. The lowest MIC values were observed for AgNP SBE Nit, in the case of C. krusei $(0.1 \mathrm{mg} / \mathrm{mL}$ for $50 \%$ inhibition) and C. guilliermondii $(0.2 \mathrm{mg} / \mathrm{mL}$ for $50 \%$ inhibition). For the AgNP SBE Ac, the lowest MICs values were also in the case of C. krusei and C. guilliermondii $(0.045 \mathrm{mg} / \mathrm{mL}$ for $50 \%$ inhibition). The highest MIC values were registered for C. auris and C. parapsilosis (AgNP SBE Ac- $0.9 \mathrm{mg} / \mathrm{mL}$ for 50\% inhibition), respectively, for C. albicans (AgNP SBE Ac- $0.732 \mathrm{mg} / \mathrm{mL}$ for $50 \%$ inhibition).

Table 1. Antifungal activity (MIC) of AgNP SBEs for Candida spp.

\begin{tabular}{ccccc}
\hline Candida spp. & \multicolumn{2}{c}{$\mathbf{5 0 \%}$ Inhibition } & \multicolumn{2}{c}{$\mathbf{1 0 0 \%}$ Inhibition } \\
\hline & $\begin{array}{c}\text { AgNP SBE Ac } \\
\mathbf{m g} / \mathbf{m L}\end{array}$ & $\begin{array}{c}\text { AgNP SBE Nit } \\
\mathbf{m g} / \mathbf{m L}\end{array}$ & $\begin{array}{c}\text { AgNP SBE } \\
\text { Ac } \mathbf{~ m g / m L}\end{array}$ & $\begin{array}{c}\text { AgNP SBE Nit } \\
\mathbf{~ m g} / \mathbf{m L}\end{array}$ \\
\hline C. albicans & 0.732 & 0.16 & 1.465 & 0.64 \\
\hline C. parapsilosis & 0.9 & 0.04 & 0.36 & 0.32 \\
\hline C. krusei & 0.045 & 0.01 & 0.09 & 0.02 \\
\hline C. auris & 0.9 & 0.08 & 0.18 & 0.16 \\
\hline C. guilliermondii & 0.045 & 0.02 & 0.09 & 0.08 \\
\hline
\end{tabular}

\subsection{The Influence of the AgNP SBEs on the Growth Rate of Candida spp.}

After 24 and 48 h of incubation, both AgNP SBEs decreased the growth of C. parapsilosis, C. krusei, and C. guilliermondii (Figure 1). In the case of C. auris, the growth rate was not inhibited by MICs of AgNP SBEs. For C. albicans, after $24 \mathrm{~h}$ of incubation, the growth rate was stimulated by both AgNP SBEs; after $48 \mathrm{~h}$, in the presence of AgNP SBE Nit, the 
growth rate was almost stationary (compared to the control), while AgNP SBE Ac inhibited the growth rate of C. albicans.
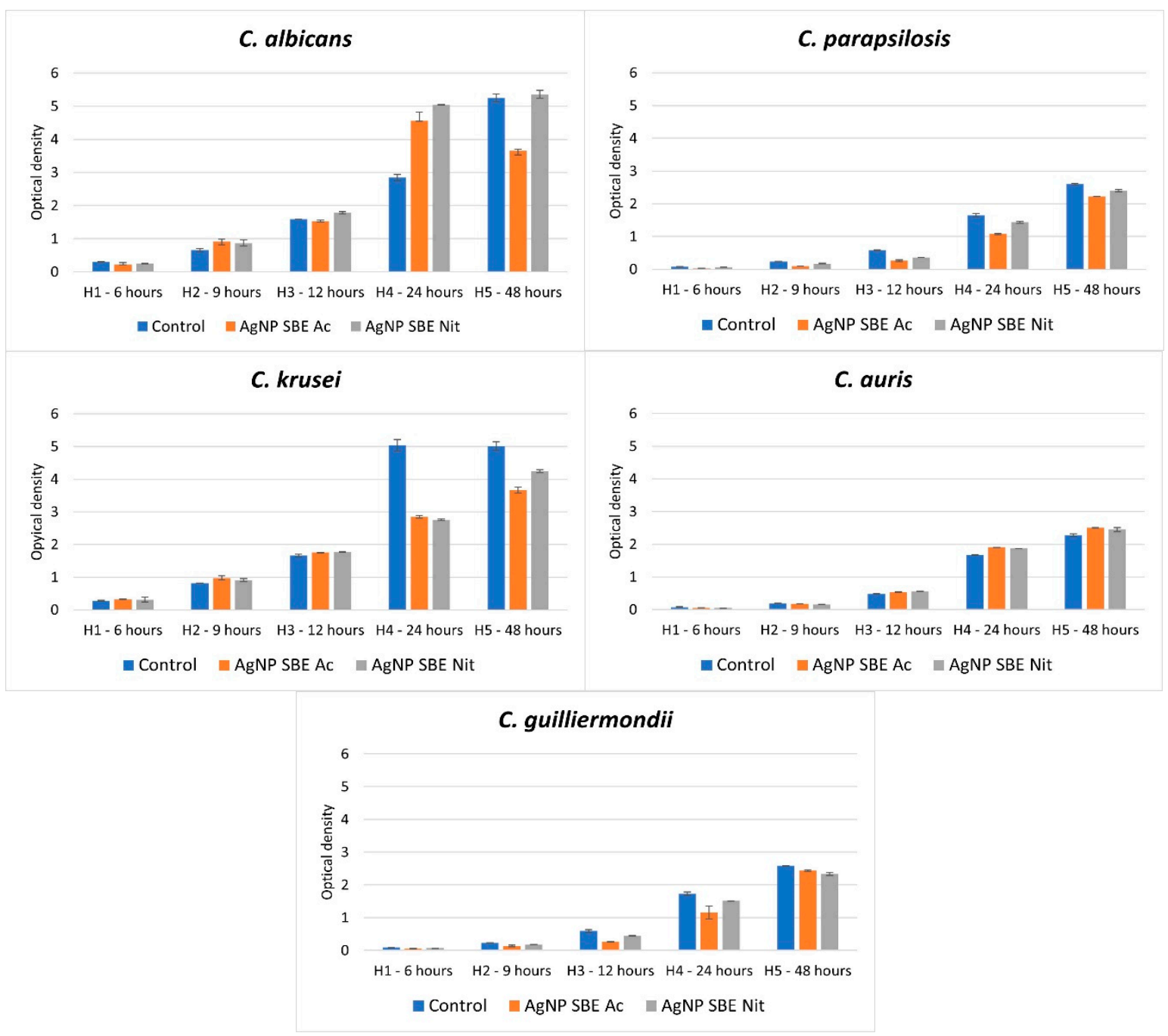

Figure 1. The influence of MICs of AgNP SBEs on the growth rate of Candida spp.

\subsection{Checkerboard Method-Fluconazole Synergy Test}

As it is presented in Figure 2, both AgNP SBEs exerted synergistic activity with different concentrations of fluconazole, for C. parapsilosis, and C. guilliermondii, with the highest number of FIC values (8) registered for C. guilliermondii, for different combinations of AgNP SBE Ac (ranging from $0.005 \mathrm{mg} / \mathrm{mL}$ to $0.02 \mathrm{mg} / \mathrm{mL}$ ) and fluconazole (ranging from $0.25 \mathrm{mg} / \mathrm{L}$ to $2 \mathrm{mg} / \mathrm{L}$ ). The lowest FIC values were registered for $C$. guilliermondii, for the combination of AgNP SBE Ac and fluconazole (FIC 0.18 for $0.005 \mathrm{mg} / \mathrm{mL}$ AgNP SBE Ac combined with $1 \mathrm{mg} / \mathrm{L}$ fluconazole, FIC 0.24 for $0.01 \mathrm{mg} / \mathrm{mL}$ AgNP SBE Ac combined with $1 \mathrm{mg} / \mathrm{L}$ fluconazole and FIC 0.25 for $0.02 \mathrm{mg} / \mathrm{mL}$ AgNP SBE Ac combined with $0.25 \mathrm{mg} /$ L fluconazole). For C. albicans, C. krusei and C. auris no synergistic activity was observed. 


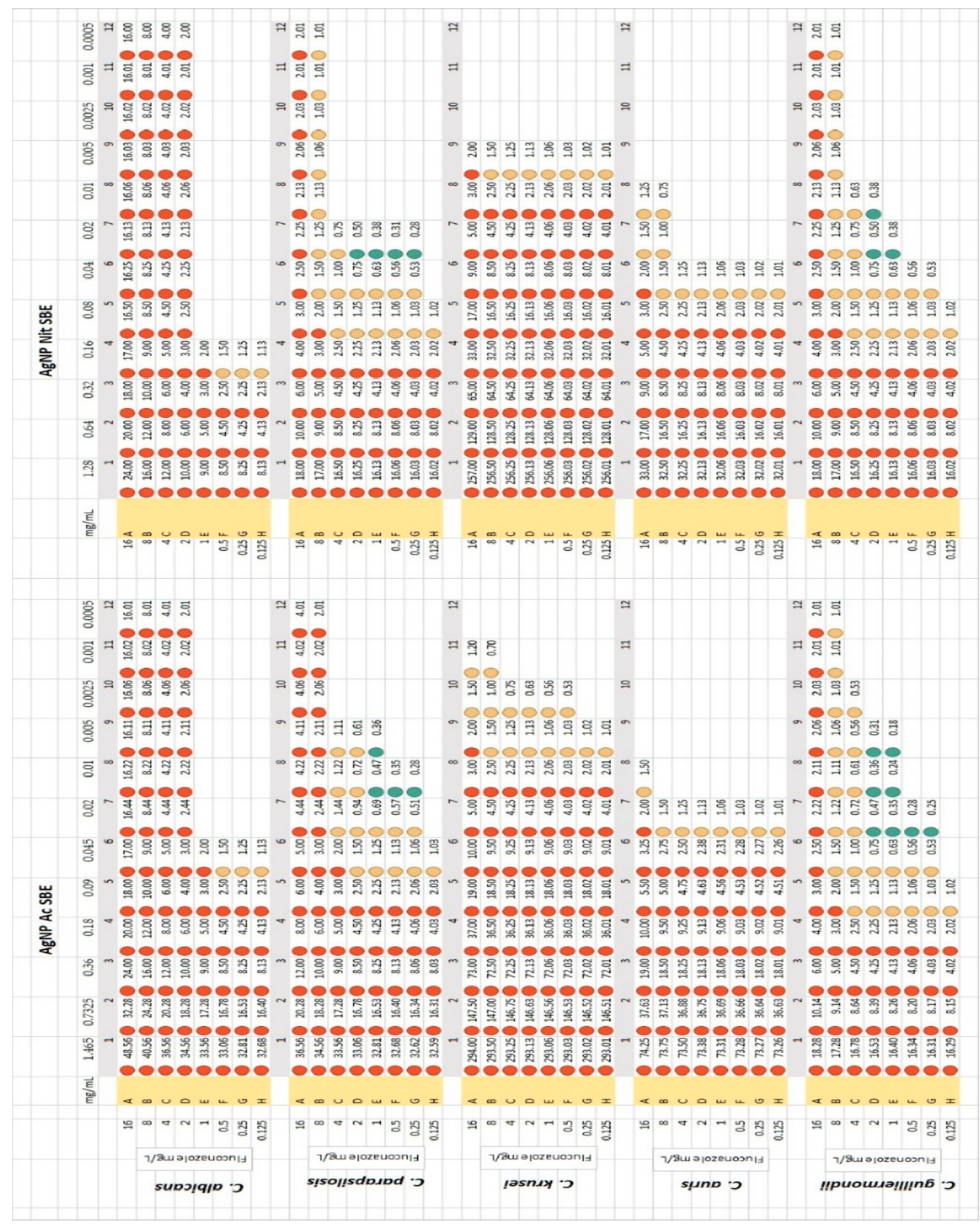

Figure 2. FICs for fluconazole synergy test in the presence of AgNP SBEs (checkerboard method). Synergistic FIC valuesmarked with green bullets, indifferent FIC values-marked with yellow bullets, antagonistic FIC values-marked with red bullets.

\subsection{The Influence of the AgNP SBEs on the Biofilm Formation}

From Figure 3, it can be observed that both the AgNP SBEs inhibited the biofilm production for C. albicans, C. auris and C. guilliermondii. The highest percent of inhibition was observed for C. guilliermondii (inhibition percent between $86.63 \%$ and $88.47 \%$ ), followed by C. albicans (inhibition percent between $27.52 \%$ and $42.2 \%$ ) and C. auris (inhibition percent between $8.23 \%$ and $29.41 \%$ ). The inhibition of the biofilm production was not related to the concentration of AgNP SBEs, as for C. albicans and C. auris the higher concentrations 
of AgNP SBEs presented a lower percent of biofilm inhibition than those for the lower concentrations of AgNP SBEs. For C. guilliermondii, the percent of biofilm inhibition was almost similar for all the tested AGNP SBEs concentrations. For C. krusei, C. parapsilosis AgNP SBEs enhanced the biofilm production on different percentages, as can be seen from Figure 3.

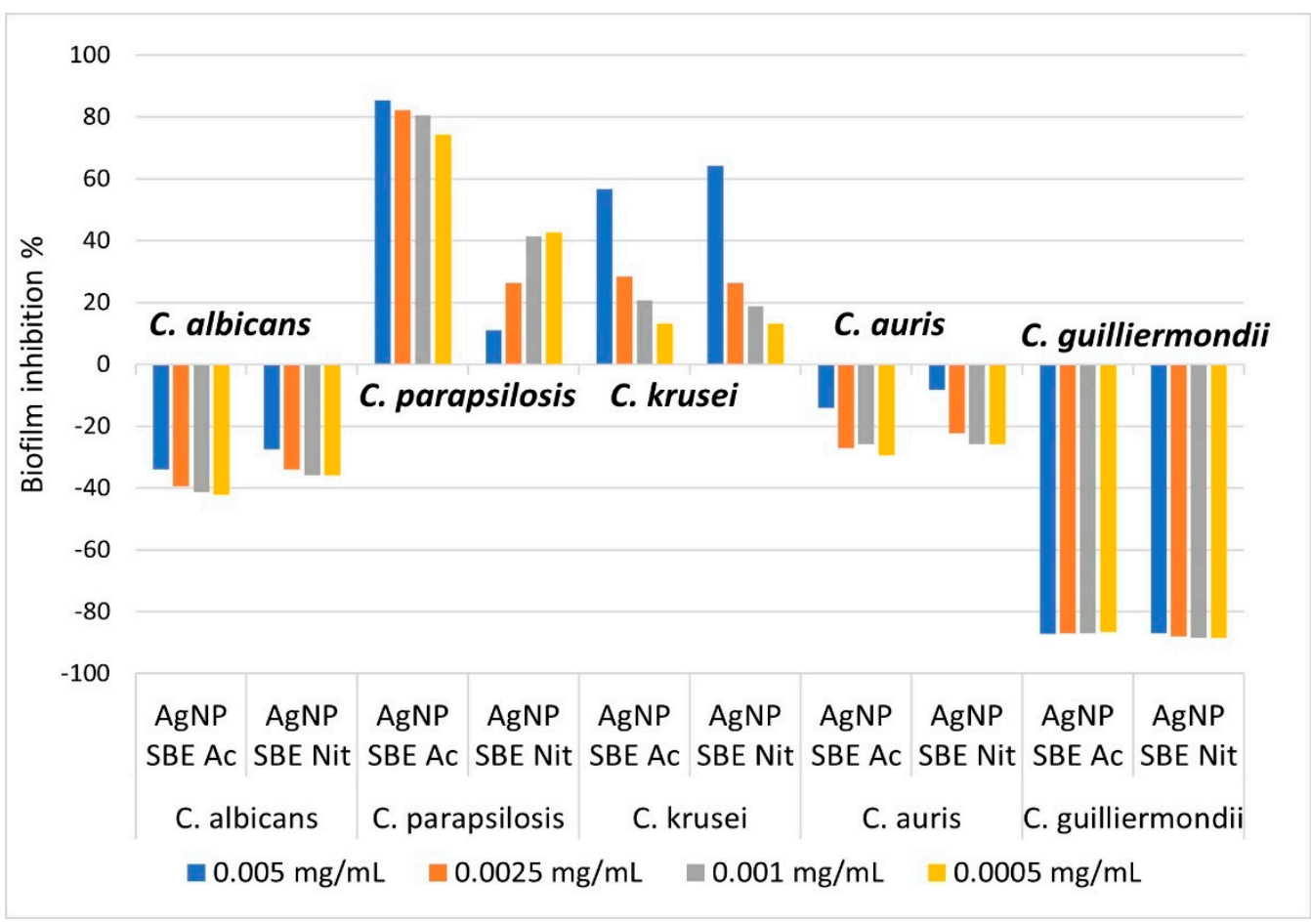

Figure 3. The influence of AgNP SBEs on Candida spp. biofilm production (\%).

2.6. The Influence of the AgNP SBEs on the Germ Tubes Production of C. albicans

The MICs of AgNP SBE Ac significantly inhibited the production of germ tubes of $C$. albicans ( $p=0.0001$ compared to both control and AgNP SBE Nit). The production of germ tubes was not influenced by MICs of AgNP SBE Nit ( $p=1$, compared to control) (Figure 4).

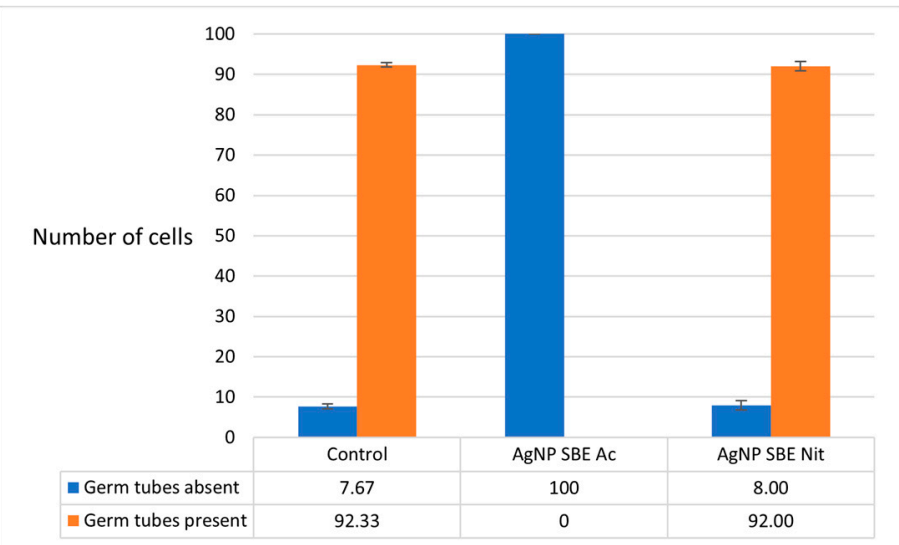

Figure 4. The influence of the AgNP SBEs on the germ tubes production of C. albicans.

2.7. The Influence of the AgNP SBEs on C. albicans Gene Expression for ALS3, SAP2, HSP70

The expression of $C$. albicans $S A P 2$ gene was down-regulated by the short time $(3 \mathrm{~h})$ treatment with MICs of AgNP SBE Ac (FC = 0.42), while the treatment with AgNP SBE Nit presented an indifferent effect for the $S A P 2$ expression $(F C=0.91$, over the 0.75 value that 
was considered as the threshold for down-regulation). The expression of C. albicans ALS3 and HSP70 gene was up-regulated by both the AgNPs MICs, with smaller FC values for ALS3 (1.36 for AgNP SBE Ac, respectively, and 2.78 for AgNP SBE Nit) than those obtained for HSP70 (3.83 for AgNP SBE Ac, respectively, and 3.03 for AgNP SBE Nit) (Figure 5).

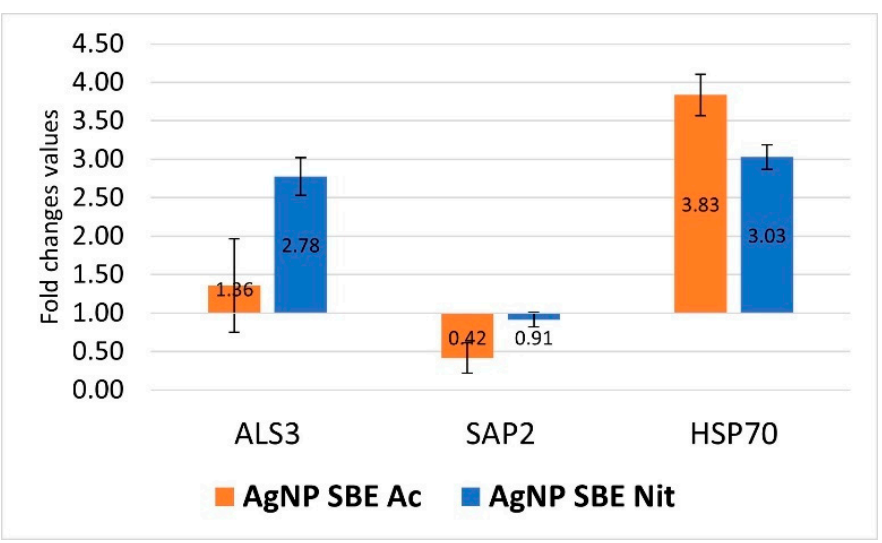

Figure 5. The influence of the AgNP SBEs on C. albicans gene expression for ALS3, SAP2, HSP70.

\section{Discussion}

It is recognized that the green bio-synthesis methods can generate pure nanoparticles, with controlled morphology and size, free from different toxic contaminants $[9,27,29]$. Due to their high content of bioactive molecules, different plant extracts not only reduce the silver ions, prevent the agglomeration of the nanoparticles [13], but also brings important antimicrobial, anti-inflammatory, antioxidant, and antitumoral activity, which sums or even enhances the AgNPs activity [30-32]. The spruce bark is an interesting option for the biosynthesis of AgNPs due to its availability, high content of gallic, vanillic acids, catechin, astringin, and biomolecules which control the formation of free radicals and presents antibacterial, antioxidant activity [33-36].

The antibacterial activity of spruce bark and the AgNPs SBEs was previously demonstrated [26-28], but their antifungal activity was not described. There are a lot of recent studies that present the antifungal activity of different AgNPs synthesized with different plant extracts against various human pathogens (AgNPs synthesized using Aloe vera leaf extract showed high antifungal activity against Aspergillus spp. and Rhizopus spp. [37]; AgNPs synthesized with a marine algae, Hypnea muciformis, showed antifungal activity against C. albicans, C. parapsilosis, and Aspergillus niger [38]) or against plant pathogens (leaf extract Ligustrum lucidum AgNPs demonstrated activity against Setosphaeria turcica, turnip leaf extract AgNPs with activity against wood-rotting pathogens [39]). To our knowledge, the antifungal activity of the AgNP SBEs was not studied so far, so our results bring important information for the biological activity of these substances. Both AgNP SBE Ac and AgNP SBE Nit presented MICs for all the studied Candida spp., with the lowest values for the AgNP SBE Nit. There are a few antifungal mechanisms already described in the literature such as adherence to the yeast cell membrane, interfering with the fatty acids or ergosterol level, reactive oxygen species production, decreasing membrane fluidity, and DNA alteration [2,40,41]. The small size of the AgNP SBEs [26] and the fact that the bioactive compounds of the plant extracts prevent the agglomeration of the AgNPs [13] might explain their antifungal activity. In our study, the lowest MIC values were observed for AgNP SBE Nit, in the case of C. krusei $(0.1 \mathrm{mg} / \mathrm{mL}$ for $50 \%$ inhibition) and C. guilliermondii $(0.2 \mathrm{mg} / \mathrm{mL}$ for $50 \%$ inhibition). For the AgNP SBE Ac, the lowest MICs values were also in the case of C. krusei and C. guilliermondii $(0.045 \mathrm{mg} / \mathrm{mL}$ for $50 \%$ inhibition). These results, along with the AgNP SBEs inhibition of the growth rate for C. parapsilosis, C. krusei and C. guilliermondii emphasizes once again the advantages of using bio-nanoparticles as treatment options, or as adjuvants, even for non-albicans Candida species. 
Another possible utility of the AgNPs comes from one of their antifungal mechanisms, respectively, that by modifying the fungal membrane permeability, the AgNPs may promote the entry of the fluconazole into the cells wherein it can interfere with the biosynthesis of the ergosterol $[42,43]$. This might be a possible explanation for our results, as for $C$. parapsilosis and C. guilliermondii, both AgNP SBEs exerted synergistic activity with different concentrations of fluconazole, with the highest number of FIC values (8) registered for $C$. guilliermondii, for different combinations of AgNP SBE Ac (ranging from $0.005 \mathrm{mg} / \mathrm{mL}$ to $0.02 \mathrm{mg} / \mathrm{mL}$ ) and fluconazole (ranging from $0.25 \mathrm{mg} / \mathrm{L}$ to $2 \mathrm{mg} / \mathrm{L}$ ). An interesting result was that for C. krusei (considered as intrinsically fluconazole-resistant strain), synergistic activity between the fluconazole and the AgNP SBEs was not observed, but for the combination of AgNP SBE Ac with fluconazole, FICs with very close values to the synergy cut-off (0.5) were registered (FIC 0.53 for $0.0025 \mathrm{mg} / \mathrm{mL}$ AgNP SBE Ac combined with $0.5 \mathrm{mg} / \mathrm{L}$ fluconazole, FIC 0.56 for $0.0025 \mathrm{mg} / \mathrm{mL}$ AgNP SBE Ac combined with $1 \mathrm{mg} / \mathrm{L}$ fluconazole). Once again, these results draw attention to the possibility of using the AgNP SBEs not only against the redundant $C$. albicans, but, even for the non-albicans Candida species, not as frequently involved in human pathologies, but, sometimes, more aggressive.

One of the important virulence factors of Candida spp. is their capacity to produces biofilms on different organic and inorganic surfaces. Inside the biofilms, Candida spp. cells, protected by the extracellular matrix, are more difficult to eradicate, making these infections a difficult challenge for the physicians, especially when multi-drug resistant strains are involved $[19,24,44]$. The small size of the green synthesized nanoparticles enables them easy access inside the biofilms matrix, making them a functional option for the inhibition of the biofilms, or as drug delivery agents [45]. Our study demonstrated that both the AgNP SBEs inhibited the biofilm production for C. albicans, C. auris and C. guilliermondii, with the highest percent of inhibition for C. guilliermondii (between $86.63 \%$ and $88.47 \%$ ), followed by C. albicans (between $27.52 \%$ and $42.2 \%$ ) and C. auris (between $8.23 \%$ and $29.41 \%$ ). The inhibition of the C. auris biofilm by Ag NPs coated with polyvinylpyrrolidone was demonstrated in another recent study [40].

The morphological transition of C. albicans to filamentous forms is another important virulence factor of this yeast, that facilitates its adherence to the host cells, invasion of the cells, and biofilm production $[19,23]$. Some recent studies reported the $C$. albicans germ tubes inhibition by different AgNPs $[23,46,47]$. Our study demonstrated that the MICs of AgNP SBE Ac significantly inhibited the production of germ tubes of C. albicans, but the production of germ tubes was not influenced by MICs of AgNP SBE Nit. The Ras-mediated signal transduction pathways might be affected by biosynthesized AgNPs, by down-regulating the expression of the genes involved in the morphological transition of C. albicans (EGE1 - cell elongation gene; TEC gene-hyphal inducer gene; TUP1, RFG1hyphal transition genes) $[23,46,48]$.

C. albicans secretes hydrolytic enzymes such as proteinases (Saps), lipases (Lip), and phospholipases (PL), which are involved in the adhesion and the penetration into the host cells. Hsps, (heat shock proteins), which mediate the response to stress for C. albicans, are involved in the dispersion of these cells inside the biofilms and the susceptibility to antifungal agents [19]. The up/down regulation of the expression of different genes might increase/decrease the virulence of the fungal strain by stimulating/inhibiting different virulence factors, encoded by the gene. Our study showed that the expression of $C$. albicans SAP2 gene was down-regulated by the short time ( $3 \mathrm{~h}$ ) treatment with MICs of AgNP SBE Ac, while the ALS3 and HSP70 genes were up-regulated by both the AgNPs MICs. ALS (agglutinin-like sequence) genes are associated with Candida albicans adhesion on the host cells and their invasion into the cells. Als3 is a protein localized on C. albicans hyphae that helps the yeast to attach to the cells and, also, to the extracellular protein matrix [19]. Even if both the AgNP SBEs inhibited the biofilm formation, and the MICs of AgNP SBE Ac significantly inhibited the production of germ tubes of $C$. albicans, the expression of C. albicans ALS3 and HSP70 gene (genes that are both involved in the biofilm formation) was up-regulated by both the AgNPs MICs. These results emphasize the 
possibility that multiple other mechanisms of actions are involved in the antifungal activity of biosynthesized AgNPs.

The results from this study and previously published ones [26-28,36] sustain the possibility of AgNP SBEs functionalization as antifungal and antibacterial agents, but more research is needed to fully understand their antimicrobial mechanisms and how these AgNPs might be used for different medical applications.

\section{Materials and Methods}

\subsection{The Synthesis of the Silver Nanoparticles}

The spruce bark (Picea abies L.) aqueous extract was obtained from spruce bark waste, according to previously published studies $[26,28]$. The silver nanoparticles (AgNPs) were synthesized and characterized following a previously published protocol [26,27]. The obtained nanoparticles solutions were silver nanoparticles produced with silver acetate and spruce bark (AgNP SBE Ac), $2.93 \mathrm{mg} \mathrm{AgNPs/mL}$, and silver nanoparticles produced with silver nitrate and spruce bark (AgNP SBE Nit), $2.56 \mathrm{mg}$ AgNPs/mL. The obtained solutions were filtered using sterile syringe filters, with $0.45 \mu \mathrm{m}$ diameter, to ensure that the work solutions were sterile.

\subsection{Fungal Strains}

Five Candida spp. were used in this study: C. albicans ATCC 90028, Candida parapsilosis ATCC 22019, C. krusei ATCC 6258, C. auris CBS 10913, C. guilliermondii 184 (Cantacuzino National Research and Development Institute for Microbiology and Immunology, Bucharest). The strains are stored at $-70{ }^{\circ} \mathrm{C}$ in the Microbiology Department from "George Emil Palade" University of Medicine, Pharmacy, Science, and Technology of Târgu Mureş and at the Laboratory of Antimicrobial Chemotherapy, Ion Ionescu de la Brad University of Life Sciences, Iași. Candida spp. were revitalized before each experiment in Sabouraud Dextrose Broth (SDB, Basingstoke, Oxoid, UK).

\subsection{Antifungal Activity of the AgNP SBES}

For the assessment of the antifungal activity of the AgNP SBEs, we performed the microdilution method recommended by EUCAST [49], with minor modification. Briefly, from $200 \mu \mathrm{L}$ of AgNP SBEs, serial two folded dilutions were performed in RPMI 2X medium (Sigma Aldrich, St. Louis, MO, USA) buffered with MOPS, in the rows of a 96 wells microtiter plate. An inoculum with approximatively $1-5 \times 10^{5} \mathrm{CFU} / \mathrm{mL}$ density was prepared, by mixing $9 \mathrm{~mL}$ RPMI with $1 \mathrm{~mL} 0.5 \mathrm{McFarland}$ fungal suspension. From this inoculum, $100 \mu \mathrm{L}$ were pipetted to the microtiter-plate's wells. A positive well (fungal inoculum + RPMI) and a negative one (RPMI medium) were performed as controls. After $36 \mathrm{~h}$ of incubation, at $37^{\circ} \mathrm{C}$, the $50 \%$ minimum inhibitory concentration (MIC) was evaluated by visual examination, in the wells where the Candida spp. growth was over $50 \%$ inhibited, comparing to the control well. The 100\% MIC was considered in the wells without visible growth. Tests were performed in triplicate.

\subsection{The Influence of the AgNP SBEs on the Growth Rate of Candida spp.}

The influence of the AgNP SBEs on the growth rate of Candida spp. was performed in $10 \mathrm{~mL}$ volume suspensions that reproduced the MICs for each tested substance. The tubes were incubated at $37^{\circ} \mathrm{C}$, for $48 \mathrm{~h}$. As growth control, we used a tube with the same volume and fungal inoculum, but without AgNPs SBEs. From these suspensions, $400 \mu \mathrm{L}$ were removed at $0,6,9,12,24,48 \mathrm{~h}$. Optical density (OD) was assessed at $600 \mathrm{~nm}$, using a spectrophotometer (BioPhotometer D30, Eppendorf, Wien, Austria). Tests were done in triplicate.

\subsection{Checkerboard Method-Fluconazole Synergy Test}

For each Candida spp. and tested AgNP SBEs, the checkerboard method [31] was performed, to evaluate if the AgNP SBEs might exert synergistic activity with different 
concentrations of fluconazole. The plates were designed to include (on the same plate) the clinical breakpoints of the tested Candida spp. (were available, according to EUCAST recommendations) [49]. From the first wells of the horizontal axis of the microtiter plates, $200 \mu \mathrm{L}$ of AgNP SBEs were serial binary diluted in $100 \mu \mathrm{L}$ distilled water. From a fluconazole (Sigma Aldrich, St. Louis, MO, USA) stock solution of $132 \mathrm{mg} / \mathrm{L}$, two folded dilutions were prepared in RPMI $2 X$, and $50 \mu \mathrm{L}$ from each of these dilutions were added on all the wells from each row of the vertical axis of the microtiter plates (the final concentration of the fluconazole in the first row was $16 \mathrm{mg} / \mathrm{L}$, while in the last row was $0.125 \mathrm{mg} / \mathrm{L}$ ). Fifty microliters of 0.5 McFarland fungal inoculum (1:10 diluted in RPMI 2X), were added in all the wells of the microtiter plates. The positive and negative controls were considered the wells from opposite corners of the microtiter plate, where the concentration of both fluconazole and AgNP SBEs were highest, respectively, lowest. After the plates were incubated at $37^{\circ} \mathrm{C}$, for $48 \mathrm{~h}$, the MICs were assessed at over $50 \%$ growth inhibition (by visual examination), and the fractional inhibitory concentration was calculated for all the wells where the fungal growth was inhibited over $50 \%$, using the following formula:

$F I C=\frac{\text { fluconazole MIC from the studied well }}{\text { fluconazole MIC }}+\frac{A g N P \text { SBE MIC from the studied well }}{A g N P \text { SBE MIC }}$

FIC values $\leq 0.5$ were interpreted as synergic effect of the tested solutions with fluconazole; FIC values between 0.5-2, were considered as an indifferent effect; if FIC values were $>2$, the effect of the tested solutions was considered antagonistic [50].

\subsection{The Influence of the AgNP SBEs on the Biofilm Production}

The influence of the AgNP SBEs on the production of biofilms was evaluated using the crystal violet staining method [51], in the MIC microtiter plates, after the MICs were assessed. The last four columns of the microtiter plates were used for evaluating the biofilm inhibition, as these were the columns in which all the Candida spp. presented full growth, for all the tested Candida strains, and the AgNP SBEs (colored solutions) were diluted enough not to influence the optical density of the well's suspensions at the spectrophotometric evaluation. After the excess RPMI medium was removed, the wells of the microtiter plates were immersed twice in sterile water, to wash away the unattached cells. Afterward, $200 \mu \mathrm{L}$ of $0.1 \%$ aqueous crystal violet solution were pipetted in each well, and the plates were incubated for $15 \mathrm{~min}$, at room temperature. After the crystal violet solution was removed, the plates were immersed three times in sterile water and kept at room temperature to evaporate the water excess. The crystal violet that remained attached to the cells was solubilized with $200 \mu \mathrm{L}$ of $30 \%$ acid acetic (room temperature, $15 \mathrm{~min}$ ). The suspensions from the wells were homogenized by gently shaking the plates, and each well's absorbance was measured (at $620 \mathrm{~nm}$, using a spectrophotometer). The positive control well was used as a control for the influence of the biofilm formation, as this well did not contain the AgNP SPEs. The biofilm inhibition was assessed using the next formula:

$$
\% \text { of biofilm inhibition }=\left(100 * \frac{\text { absorbance value of the assessed well }}{\text { absorbance value of the control well }}\right)-100
$$

\subsection{The Influence of the AgNP SBEs on the Germ Tubes Production of C. albicans}

To evaluate how the AgNP SBE influence the C. albicans germ tubes production, MICs of the AgNP SBEs were replicated in a $0.5 \mathrm{~mL}$ serum volume and homogenized with the same volume of $C$. albicans suspension $(0.5 \mathrm{McF}$ arland). For the germ tubes production control, $0.5 \mathrm{~mL}$ serum was mixed with $0.5 \mathrm{~mL}$ fungal suspension. The tubes were incubated at $36^{\circ} \mathrm{C}$, for $2 \mathrm{~h}$, in a water bath. The number of the germ tubes $/ 100$ cells was assessed by microscopically examining wet mounts (prepared from $25 \mu \mathrm{L}$ of the incubated suspensions). Tests were performed in triplicate. 


\subsection{The Influence of the AgNP SBEs on C. albicans Gene Expression for ALS3, SAP2, HSP70}

C. albicans was revitalized in SDB, by incubating it overnight at $37^{\circ} \mathrm{C}$, in an orbital shaker. One milliliter of 2.1 AU (OD measured at $600 \mathrm{~nm}$-BioPhotometer D30, Eppendorf, Austria, Wien) was centrifuged at $5000 \mathrm{rpm}$ for $5 \mathrm{~min}$; the obtained sediment was suspended in $1.5 \mathrm{~mL}$ of AgNP SBEs MICs prepared with SDB, and incubated for three hours, in a thermomixer, at $37^{\circ} \mathrm{C}$.

After the incubation, the AgNP SBEs treated samples were centrifugated $5 \mathrm{~min}$ at $5000 \mathrm{rpm}$, and the sediment was resuspended in $500 \mu \mathrm{L}$ TE buffer. Two cycles of freezing and heating $\left(-70{ }^{\circ} \mathrm{C}\right.$, respectively, and $\left.95^{\circ} \mathrm{C}\right)$ were performed to damage the fungal cell wall, followed by the digestion of the cell wall with Arthrobacter luteus lyticase (Sigma Aldrich, St. Louis, MO, USA). Afterward, the lyticase was neutralized by heating the samples for $10 \mathrm{~min}$ at $94^{\circ} \mathrm{C}$, and silica-based spin columns were used for RNA purification. The unwanted DNA from the elutes was removed using DNase I solution (Thermo Scientific, Waltham, MA, USA). After the purity and concentration of the obtained RNA (ng/ $\mu \mathrm{L})$ were assessed by nanodrop reading (Eppendorf BioPhotometer D30, Wien, Austria), reversetranscription was carried out (GoScript Reverse Transcription System, Promega, Madison, WI, USA) to produce complementary DNA.

QuantStudio 5 Real-Time PCR System (Thermo Fisher, Waltham, MA, USA) was used to perform the RT-PCR assay in a final volume of $20 \mu \mathrm{L}$. The following primers were used: for ACT1-forward 5'-TTG TTG ACC GAA GCT CCA ATG-3' and reverse 5'-ACG TGA GTA ACA CCA TCA CCA-3'; for ALS3-forward 5'-CCA CTT CAC AAT CCC CAT C $-3^{\prime}$ and reverse $5^{\prime}-\mathrm{CAG}$ CAG TAG TAG TAA CAG TAG TAG TTT CAT C $-3^{\prime}$; for SAP2-forward 5'-GAT GCT GCC ACG GGA CAA AT- $3^{\prime}$ and reverse $5^{\prime}$-AGA AGC AGC AAA TTC GGA AGC- $3^{\prime}$; for HSP70 - forward $5^{\prime}$-TGG TAT TCC ACC AGC TCC AAG-3' and reverse 5'-CAA CTT CTT CAA CAG TTG GTC CAC- $3^{\prime}$ ). Afterward, the ALS3, SAP2, $H S P 70$ expression levels were adjusted by reporting to the $A C T 1$ levels, using the Delt-Delta Ct Method [52]. Fold changes (FC) values $<0.75$ were interpreted as down-regulation, while FC $>1.25$, were considered up-regulation. Tests were done in triplicate.

\section{Conclusions}

Both the AgNP SBEs presented different degrees of inhibitions for all the tested Candida spp, with an overall better activity for the AgNP SBE Nit. The growth rate of $C$. parapsilosis, C. krusei, and C. guilliermondii was inhibited by both the AgNP SBEs.

Both AgNP SBEs exerted synergistic activity with different concentrations of fluconazole for C. parapsilosis and C. guilliermondii, drawing attention to the possibility of functionalization these nanoparticles as adjuvants for the classical antifungal agents.

Both the AgNP SBEs inhibited the biofilm production for C. albicans, C. auris and C. guilliermondii, with a higher percent of inhibition for C. guilliermondii, followed by $C$. albicans and C. auris. MICs of AgNP SBE Ac significantly inhibited the production of germ tubes of $C$. albicans, but the production of germ tubes was not influenced by MICs of AgNP SBE Nit. The expression of $C$. albicans SAP2 gene was down-regulated by the short-time treatment with MICs of AgNP SBE Ac, while ALS3 and HSP70 gene were up-regulated by both the AgNPs MICs. Our results conclude that these nanoparticles might be an option as modulating agents for the different virulence factors of Candida spp.

The overall antifungal activity of the AgNP SBEs emphasizes the possibility of using them as treatment/adjuvant options, not only against the redundant $C$. albicans, but, even for the non-albicans Candida species, not as frequently involved in human pathologies, but sometimes more aggressive.

Author Contributions: Conceptualization, A.D.M., A.M., C.N.C. and C.T.; methodology, A.D.M., A.M., C.N.C., F.T. and C.T.; software, A.D.M., A.M., C.N.C. and A.C.; validation, A.D.M., A.M., C.N.C., F.T., M.M. and L.B.; formal analysis, A.D.M., A.M., C.N.C., A.C., M.M., F.T. and L.B.; investigation, A.D.M., A.M., C.N.C., A.C., M.M., F.T., L.B. and C.T.; resources, A.D.M., A.M., C.N.C., M.M. and F.T.; data curation, A.D.M., C.N.C. and A.M.; writing-A.D.M., A.M. and C.N.C.; writing-review and editing, A.D.M., A.M., C.N.C., A.C., M.M., C.T., F.T. and L.B.; visualization, A.D.M., A.M., C.N.C., 
F.T., M.M. and L.B.; supervision, A.D.M., A.M. and C.N.C.; project administration, A.D.M. and A.M.; funding acquisition, A.M. All authors have read and agreed to the published version of the manuscript.

Funding: This work was supported by George Emil Palade University of Medicine, Pharmacy, Science, and Technology of Târgu Mureș Research Grant number 294/5/14.1.2020.

Institutional Review Board Statement: Not applicable.

Informed Consent Statement: Not applicable.

Conflicts of Interest: The authors declare no conflict of interest.

\section{References}

1. New Report Calls for Urgent Action to Avert Antimicrobial Resistance Crisis. Available online: https://www.who.int/news/ item/29-04-2019-new-report-calls-for-urgent-action-to-avert-antimicrobial-resistance-crisis (accessed on 17 September 2021).

2. Radhakrishnan, V.S.; Reddy Mudiam, M.K.; Kumar, M.; Dwivedi, S.P.; Singh, S.P.; Prasad, T. Silver Nanoparticles Induced Alterations in Multiple Cellular Targets, Which Are Critical for Drug Susceptibilities and Pathogenicity in Fungal Pathogen (Candida Albicans). Int. J. Nanomed. 2018, 13, 2647-2663. [CrossRef]

3. Coman, A.N.; Mare, A.; Tanase, C.; Bud, E.; Rusu, A. Silver-Deposited Nanoparticles on the Titanium Nanotubes Surface as a Promising Antibacterial Material into Implants. Metals 2021, 11, 92. [CrossRef]

4. Loo, Y.Y.; Rukayadi, Y.; Nor-Khaizura, M.-A.-R.; Kuan, C.H.; Chieng, B.W.; Nishibuchi, M.; Radu, S. In Vitro Antimicrobial Activity of Green Synthesized Silver Nanoparticles Against Selected Gram-Negative Foodborne Pathogens. Front. Microbiol. 2018, 9, 1555. [CrossRef]

5. Siddiqi, K.S.; Husen, A.; Rao, R.A.K. A Review on Biosynthesis of Silver Nanoparticles and Their Biocidal Properties. J. Nanobiotechnol. 2018, 16, 14. [CrossRef]

6. Hamouda, R.A.; Hussein, M.H.; Abo-elmagd, R.A.; Bawazir, S.S. Synthesis and Biological Characterization of Silver Nanoparticles Derived from the Cyanobacterium Oscillatoria Limnetica. Sci. Rep. 2019, 9, 13071. [CrossRef] [PubMed]

7. Agnihotri, S.; Mukherji, S.; Mukherji, S. Size-Controlled Silver Nanoparticles Synthesized over the Range 5-100 Nm Using the Same Protocol and Their Antibacterial Efficacy. RSC Adv. 2013, 4, 3974-3983. [CrossRef]

8. Quintero-Quiroz, C.; Acevedo, N.; Zapata-Giraldo, J.; Botero, L.E.; Quintero, J.; Zárate-Triviño, D.; Saldarriaga, J.; Pérez, V.Z. Optimization of Silver Nanoparticle Synthesis by Chemical Reduction and Evaluation of Its Antimicrobial and Toxic Activity. Biomater. Res. 2019, 23, 27. [CrossRef] [PubMed]

9. Rauwel, P.; Küünal, S.; Ferdov, S.; Rauwel, E. A Review on the Green Synthesis of Silver Nanoparticles and Their Morphologies Studied via TEM. Adv. Mater. Sci. Eng. 2015, 2015, e682749. [CrossRef]

10. Granbohm, H.; Larismaa, J.; Ali, S.; Johansson, L.-S.; Hannula, S.-P. Control of the Size of Silver Nanoparticles and Release of Silver in Heat Treated SiO2-Ag Composite Powders. Materials 2018, 11, 80. [CrossRef] [PubMed]

11. Murphy, M.; Ting, K.; Zhang, X.; Soo, C.; Zheng, Z. Current Development of Silver Nanoparticle Preparation, Investigation, and Application in the Field of Medicine. J. Nanomater. 2015, 2015, e696918. [CrossRef]

12. Dakal, T.C.; Kumar, A.; Majumdar, R.S.; Yadav, V. Mechanistic Basis of Antimicrobial Actions of Silver Nanoparticles. Front. Microbiol. 2016, 7, 1831. [CrossRef] [PubMed]

13. Ahmad, N.; Sharma, S.; Alam, M.K.; Singh, V.N.; Shamsi, S.F.; Mehta, B.R.; Fatma, A. Rapid Synthesis of Silver Nanoparticles Using Dried Medicinal Plant of Basil. Colloids Surf. B Biointerfaces 2010, 81, 81-86. [CrossRef] [PubMed]

14. Wang, L.; Hu, C.; Shao, L. The Antimicrobial Activity of Nanoparticles: Present Situation and Prospects for the Future. Int. J. Nanomed. 2017, 12, 1227-1249. [CrossRef] [PubMed]

15. Sánchez-López, E.; Gomes, D.; Esteruelas, G.; Bonilla, L.; Lopez-Machado, A.L.; Galindo, R.; Cano, A.; Espina, M.; Ettcheto, M.; Camins, A.; et al. Metal-Based Nanoparticles as Antimicrobial Agents: An Overview. Nanomaterials 2020, 10, 292. [CrossRef]

16. Bankier, C.; Matharu, R.K.; Cheong, Y.K.; Ren, G.G.; Cloutman-Green, E.; Ciric, L. Synergistic Antibacterial Effects of Metallic Nanoparticle Combinations. Sci. Rep. 2019, 9, 16074. [CrossRef]

17. Arendrup, M.C.; Patterson, T.F. Multidrug-Resistant Candida: Epidemiology, Molecular Mechanisms, and Treatment. J. Infect. Dis. 2017, 216, S445-S451. [CrossRef]

18. Deorukhkar, S.C.; Saini, S.; Mathew, S. Non-Albicans Candida Infection: An Emerging Threat. Interdiscip. Perspect. Infect. Dis. 2014, 2014, 615958. [CrossRef]

19. Ciurea, C.N.; Kosovski, I.-B.; Mare, A.D.; Toma, F.; Pintea-Simon, I.A.; Man, A. Candida and Candidiasis-Opportunism Versus Pathogenicity: A Review of the Virulence Traits. Microorganisms 2020, 8, 857. [CrossRef]

20. Silva, S.; Negri, M.; Henriques, M.; Oliveira, R.; Williams, D.W.; Azeredo, J. Adherence and Biofilm Formation of Non-Candida Albicans Candida Species. Trends Microbiol. 2011, 19, 241-247. [CrossRef]

21. Phan, Q.T.; Myers, C.L.; Fu, Y.; Sheppard, D.C.; Yeaman, M.R.; Welch, W.H.; Ibrahim, A.S.; Edwards, J.E.; Filler, S.G. Als3 Is a Candida Albicans Invasin That Binds to Cadherins and Induces Endocytosis by Host Cells. PLoS Biol. 2007, 5, e64. [CrossRef]

22. Moteriya, P.; Padalia, H.; Chanda, S. Characterization, Synergistic Antibacterial and Free Radical Scavenging Efficacy of Silver Nanoparticles Synthesized Using Cassia Roxburghii Leaf Extract. J. Genet. Eng. Biotechnol. 2017, 15, 505-513. [CrossRef] [PubMed] 
23. Jalal, M.; Ansari, M.A.; Alzohairy, M.A.; Ali, S.G.; Khan, H.M.; Almatroudi, A.; Siddiqui, M.I. Anticandidal Activity of Biosynthesized Silver Nanoparticles: Effect on Growth, Cell Morphology, and Key Virulence Attributes of Candida Species. IJN 2019, 14, 4667-4679. [CrossRef] [PubMed]

24. Jeffery-Smith, A.; Taori, S.K.; Schelenz, S.; Jeffery, K.; Johnson, E.M.; Borman, A.; Candida auris Incident Management Team; Manuel, R.; Brown, C.S. Candida Auris: A Review of the Literature. Clin. Microbiol. Rev. 2018, 31, e00029-17. [CrossRef] [PubMed]

25. Vazquez-Munoz, R.; Lopez, F.D.; Lopez-Ribot, J.L. Silver Nanoantibiotics Display Strong Antifungal Activity Against the Emergent Multidrug-Resistant Yeast Candida Auris Under Both Planktonic and Biofilm Growing Conditions. Front. Microbiol. 2020, 11, 1673. [CrossRef] [PubMed]

26. Tanase, C.; Berta, L.; Coman, N.A.; Roșca, I.; Man, A.; Toma, F.; Mocan, A.; Nicolescu, A.; Jakab-Farkas, L.; Biró, D.; et al. Antibacterial and Antioxidant Potential of Silver Nanoparticles Biosynthesized Using the Spruce Bark Extract. Nanomaterials 2019, 9, 1541. [CrossRef]

27. Tanase, C.; Berta, L.; Mare, A.; Man, A.; Talmaciu, A.I.; Roșca, I.; Mircia, E.; Volf, I.; Popa, V.I. Biosynthesis of Silver Nanoparticles Using Aqueous Bark Extract of Picea Abies L. and Their Antibacterial Activity. Eur. J. Wood Prod. 2020, 78, 281-291. [CrossRef]

28. Tanase, C.; Cosarca, S.; Toma, F.; Mare, A.; Cosarca, A.; Man, A.; Miklos, A.; Imre, S. Antibacterial Activities of Spruce Bark (Picea Abies L.) Extract and Its Components Against Human Pathogens. Rev. Chim. 2018, 69, 1462-1467. [CrossRef]

29. Garibo, D.; Borbón-Nuñez, H.A.; de León, J.N.D.; García Mendoza, E.; Estrada, I.; Toledano-Magaña, Y.; Tiznado, H.; OvalleMarroquin, M.; Soto-Ramos, A.G.; Blanco, A.; et al. Green Synthesis of Silver Nanoparticles Using Lysiloma Acapulcensis Exhibit High-Antimicrobial Activity. Sci. Rep. 2020, 10, 12805. [CrossRef]

30. Ahmed, S.; Ahmad, M.; Swami, B.L.; Ikram, S. A Review on Plants Extract Mediated Synthesis of Silver Nanoparticles for Antimicrobial Applications: A Green Expertise. J. Adv. Res. 2016, 7, 17-28. [CrossRef]

31. Jain, S.; Mehata, M.S. Medicinal Plant Leaf Extract and Pure Flavonoid Mediated Green Synthesis of Silver Nanoparticles and Their Enhanced Antibacterial Property. Sci. Rep. 2017, 7, 15867. [CrossRef]

32. Vanlalveni, C.; Lallianrawna, S.; Biswas, A.; Selvaraj, M.; Changmai, B.; Rokhum, S.L. Green Synthesis of Silver Nanoparticles Using Plant Extracts and Their Antimicrobial Activities: A Review of Recent Literature. RSC Adv. 2021, 11, 2804-2837. [CrossRef]

33. Co, M.; Fagerlund, A.; Engman, L.; Sunnerheim, K.; Sjöberg, P.J.R.; Turner, C. Extraction of Antioxidants from Spruce (Picea Abies) Bark Using Eco-Friendly Solvents. Phytochem. Anal. 2012, 23, 1-11. [CrossRef] [PubMed]

34. Ignat, I.; Radu, D.G.; Volf, I.; Pag, A.I.; Popa, V.I. Antioxidant and Antibacterial Activities of Some Natural Polyphenols. Cellulose Chem. Technol. 2013, 47, 387-399.

35. Kuppusamy, P.; Yusoff, M.M.; Maniam, G.P.; Govindan, N. Biosynthesis of Metallic Nanoparticles Using Plant Derivatives and Their New Avenues in Pharmacological Applications-An Updated Report. Saudi Pharm. J. 2016, 24, 473-484. [CrossRef] [PubMed]

36. Coșarcă, S.-L.; Moacă, E.-A.; Tanase, C.; Muntean, D.L.; Pavel, I.Z.; Dehelean, C.A. Spruce and Beech Bark Aqueous Extracts: Source of Polyphenols, Tannins and Antioxidants Correlated to in Vitro Antitumor Potential on Two Different Cell Lines. Wood Sci. Technol. 2019, 53, 313-333. [CrossRef]

37. Medda, S.; Hajra, A.; Dey, U.; Bose, P.; Mondal, N.K. Biosynthesis of Silver Nanoparticles from Aloe Vera Leaf Extract and Antifungal Activity against Rhizopus Sp. and Aspergillus Sp. Appl. Nanosci. 2015, 5, 875-880. [CrossRef]

38. Devi, J.S.; Bhimba, B.V. Antibacterial and Antifungal Activity of Silver Nanoparticles Synthesized Using Hypnea Muciformis. Biosci. Biotechnol. Res. Asia 2014, 11, 235-238. [CrossRef]

39. Narayanan, K.B.; Park, H.H. Antifungal Activity of Silver Nanoparticles Synthesized Using Turnip Leaf Extract (Brassica Rapa L.) against Wood Rotting Pathogens. Eur. J. Plant Pathol. 2014, 140, 185-192. [CrossRef]

40. Vazquez-Muñoz, R.; Avalos-Borja, M.; Castro-Longoria, E. Ultrastructural Analysis of Candida Albicans When Exposed to Silver Nanoparticles. PLoS ONE 2014, 9, e108876. [CrossRef]

41. Hwang, I.; Lee, J.; Hwang, J.H.; Kim, K.-J.; Lee, D.G. Silver Nanoparticles Induce Apoptotic Cell Death in Candida Albicans through the Increase of Hydroxyl Radicals. FEBS J. 2012, 279, 1327-1338. [CrossRef]

42. Longhi, C.; Santos, J.P.; Morey, A.T.; Marcato, P.D.; Durán, N.; Pinge-Filho, P.; Nakazato, G.; Yamada-Ogatta, S.F.; Yamauchi, L.M Combination of Fluconazole with Silver Nanoparticles Produced by Fusarium Oxysporum Improves Antifungal Effect against Planktonic Cells and Biofilm of Drug-Resistant Candida Albicans. Med. Mycol. 2016, 54, 428-432. [CrossRef]

43. Kim, K.-J.; Sung, W.S.; Suh, B.K.; Moon, S.-K.; Choi, J.-S.; Kim, J.G.; Lee, D.G. Antifungal Activity and Mode of Action of Silver Nano-Particles on Candida Albicans. Biometals 2009, 22, 235-242. [CrossRef] [PubMed]

44. Lara, H.H.; Romero-Urbina, D.G.; Pierce, C.; Lopez-Ribot, J.L.; Arellano-Jiménez, M.J.; Jose-Yacaman, M. Effect of Silver Nanoparticles on Candida Albicans Biofilms: An Ultrastructural Study. J Nanobiotechnol. 2015, 13, 91. [CrossRef] [PubMed]

45. Koo, H.; Allan, R.N.; Howlin, R.P.; Hall-Stoodley, L.; Stoodley, P. Targeting Microbial Biofilms: Current and Prospective Therapeutic Strategies. Nat. Rev. Microbiol. 2017, 15, 740-755. [CrossRef]

46. Jalal, M.; Ansari, M.A.; Ali, S.G.; Khan, H.M.; Rehman, S. Anticandidal Activity of Bioinspired ZnO NPs: Effect on Growth, Cell Morphology and Key Virulence Attributes of Candida Species. Artif. Cells Nanomed. Biotechnol. 2018, 46, 912-925. [CrossRef]

47. Mudiar, R.; Kelkar-Mane, V. Original Research Article (Experimental): Targeting Fungal Menace through Copper Nanoparticles and Tamrajal. J. Ayurveda Integr. Med. 2020, 11, 316-321. [CrossRef] [PubMed]

48. Halbandge, S.D.; Jadhav, A.K.; Jangid, P.M.; Shelar, A.V.; Patil, R.H.; Karuppayil, S.M. Molecular Targets of Biofabricated Silver Nanoparticles in Candida Albicans. J. Antibiot. 2019, 72, 640-644. [CrossRef] 
49. Arendrup, M.C.; Meletiadis, J.; Mouton, J.W.; Lagrou, K.; Hamal, P.; Guinea, J. Eucast Definitive Document e.def 7.3.2. p. 21. Available online: https://www.eucast.org/astoffungi/methodsinantifungalsusceptibilitytesting/susceptibility_testing_of_ yeasts / 2020 (accessed on 17 September 2021).

50. Orhan, G.; Bayram, A.; Zer, Y.; Balci, I. Synergy Tests by E Test and Checkerboard Methods of Antimicrobial Combinations against Brucella Melitensis. J. Clin. Microbiol. 2005, 43, 140-143. [CrossRef]

51. Khan, S.N.; Khan, S.; Iqbal, J.; Khan, R.; Khan, A.U. Enhanced Killing and Antibiofilm Activity of Encapsulated Cinnamaldehyde against Candida Albicans. Front. Microbiol. 2017, 8, 1641. [CrossRef]

52. Pfaffl, M.W. A New Mathematical Model for Relative Quantification in Real-Time RT-PCR. Nucleic Acids Res. 2001, 29 , e45. [CrossRef] 